\title{
Efektivitas Media Pembelajaran E-Lumak Berbasis Moodle dan Tingkat Pendapatan Orang Tua Terhadap Hasil Belajar Statistik Pendidikan di Masa Pandemi Covid-19
}

\author{
Usman $^{1}$, Roni Amaludin ${ }^{2}$, Wa Ode Sari Amalia ${ }^{3}$, Muliyani ${ }^{4}$ \\ 1, 2,3,4 Universitas Muhammadiyah Kendari \\ Jalan K.H Ahmad Dahlan No. 10 Kota Kendari, Sulawesi Tenggara, Indonesia \\ usman@umkendari.ac.id
}

\begin{abstract}
This study aims to study the effect of moodle-based e-lumak learning media and the level of parents' income on learning outcomes of PG-PAUD students during the Covid-19 pandemic. This type of research is a quasiexperimental design with a randomized control group design. The research was carried out in the 2020/2021 academic year on PG-PAUD Muhammadiyah University of Kendari students as samples. The data analysis technique is descriptive analysis and inferential analysis. Based on the results of the discussion, the conclusions in the study are as follows: (1) The learning outcomes of students who are taught using moodle-based e-Lumak learning media and who have a parental opinion level above average have an average of 84.42 and higher than students who is taught using google classroom media; (2) There is an effect of e-Lumak-based learning media and the level of parents' income, including its simultaneous interaction on the average student learning outcomes during the Covid-19 pandemic; (3) There is a difference in the mean learning outcomes for students who are taught using moodle-based e-Lumak learning media compared to students who are taught using a special google classroom-based learning model for students with above and below average parental income levels.
\end{abstract}

Keywords: E-lumak, Parents Income Levels, Learning Outcomes

\begin{abstract}
Abstrak
Penelitian ini bertujuan untuk mempelajari pengaruh media pembelajaran e-lumak berbasis moodle dan tingkat pendapatan orang tua terhadap hasil belajar mahasiswa PG-PAUD di masa pandemi covid-19. Jenis penelitian ini adalah eksperimen kuasi dengan desain randomized control group desain. Penelitian dilaksanakan tahun ajaran 2020/2021 pada mahasiswa PG-PAUD Universitas Muhammadiyah kendari sebagai sampel. Teknik analisis data adalah analisis deksriptif dan analisis inferensial. Berdasarkan hasil dan pembahasan maka kesimpulan dalam penelitian adalah sebagai berikut: (1) Hasil belajar mahasiswa yang diajar dengan media pembelajaran e-lumak dan yang memiliki tingkat pendapat orangtua di atas rata-rata mempunyai rata-rata 84,42 dan lebih tinggi dibanding mahasiswa yang diajar dengan media google classroom; (2) Terdapat pengaruh media pembelajaran e-lumak dan tingkat pendapatan orang tua termasuk interaksinya secara simultan terhadap rerata hasil belajar mahasiswa di masa pandemi covid-19; (3) Terdapat perbedaan rerata hasil belajar untuk mahasiswa yang diajar dengan media pembelajaran e-lumak dibanding mahasiswa yang diajar dengan model pembelajaran berbasis google classroom khusus untuk mahasiswa yang tingkat pendapatan orang tua di atas dan di bawah rata-rata.
\end{abstract}

Kata kunci: E-lumak, Pendapatan Orangtua, Hasil belajar

Copyright (c) 2021 Usman, Roni Amaludin, Wa Ode Sari Amalia, Muliyani

$\llbracket$ Corresponding author: Usman

Email Address: usman@umkendari.ac.id (Jl. K.H., Ahmad Dahlan No.10 Kota Kendari, Sulawesi Tenggara)

Received 16 Februari 2021, Accepted 27 Februari 2021, Published 02 Maret 2021

\section{PENDAHULUAN}

Pada zaman sekarang keseharian manusia tidak dapat terlepas dari teknologi, mulai dari pekerjaan, bermain, bahkan dalam pendidikan (Rifai et al., 2020). Pendidikan dewasa ini bukan hanya difokuskan untuk memenuhi target kurikulum, namun menuntut adanya pemahaman kepada mahasiswa mengenai pendidikan. Pemahaman yang dimaksud tidak sekadar menghafal materi pelajaran, tetapi lebih menekankan pada kegiatan proses pembelajaran. Agar hasil pendidikan sesuai 
dengan tujuan yang diharapkan maka antara dosen dan mahasiswa harus mampu melaksanakan proses pembelajaran dengan maksimal baik tatap muka di kelas maupun secara online.

Proses pembelajaran yang dimaksud yaitu seorang dosen memerlukan keahlian dalam memilih dan melaksanakan cara mengajar yang terbaik di kelas dan online dan mahasiswa dapat menerimannya dengan baik. Seorang dosen harus mampu beriteraksi dengan baik terhadap mahasiswa, dan sebaliknya. Proses pembelajaran yang dilakukan oleh pengajar dan diikuti oleh mahasiswa akan menghasilkan perubahan-perubahan dalam diri mahasiswa tersebut yang perubahan tersebut bersifat positif. Untuk mengetahui sampai seberapa jauh perubahan yang terjadi, perlu adanya penilaian. Begitu juga dengan yang terjadi pada seorang mahasiswa yang mengikuti suatu pendidikan selalu diadakan penilaian.

Masa pandemi covid-19 adalah masa dimana covid-19 yang menular di seluruh dunia dan mematikan sehingga membatasi kehidupan sosial masyarakat (Al-Fatih et al., 2020). Di samping itu, pandemi covid-19 juga mempengaruhi tatanan kehidupan masyarakat baik dunia ekonomi, politik, budaya dan pendidikan (World Health Organizaton, 2020). Proses pembelajaran di masa pandemi covid-1`9 hanya mampu mengukur dua aspek yaitu kognitif dan psikomotorik. Aspek afektif tidak mampu dinilai oleh seorang dosen. Hal ini dikarenakan antara dosen dan mahasiswa tidak saling bertatap muka secara langsung.

Pandemi covid-19 mempengaruhi semua aktivitas kehidupan manusia mulai aktivitas olahraga, perkantoran, bahkan sampai pada hubungan transedental bagi seluruh pemeluk agama di dunia tidak terkecuali dengan bidang pendidikan. Aktivitas pendidikan yang sangat lekat dengan interaksi yang melibatkan banyak orang; pendidik dengan para peserta didik dalam satu lingkungan belajar secara langsung bertatap muka. Karena pandemi covid-19 interaksi secara langsung dihentikan (social distancing) dan diganti dengan aktivitas pembelajaran jarak jauh (daring) dengan memanfaatkan media internet (Hewi \& Asnawati, 2020).

Pada masa pandemi covid-19, pemanfaatan platform online semakin meningkat dalam dunia pendidikan, khususnya di perguruan tinggi. Platforn online yang sering digunakan oleh perguryan tinggi Universitas Muhammadiyah Kendari adalah zoom cloud meeting, google meet, lark, webex, cloudx telkomsel, dan google classroom. Semua platform yang digunakan masing-masing memiliki kelebihan dan kekuarangan. Kecanggihan teknologi informasi memfasilitasi pembelajaran selakyaknya metode $c$-learning, meskipun mahasiswa dan dosen tidak bertemu langsung dalam suatu ruang kelas. Salah satu kekurangannya adalah platform yang digunakan belum bisa dipantau secara online oleh pihak pimpinan mengenai pelaksanaan pembelajaran oleh dosen. Oleh karena itu, Universitas Muhammadiyah Kendari melatih seluruh dosen dalam penggunaan e-lumak (el-learning Universitas Muhammadiyah Kendari) untuk pembelajaran di masa pandemi covid-19. E-lumak memiliki kelebihan dalam hal pengawasan pimpinan kepada dosen mengenai pelaksanaan pembelajaran. 
(Herayanti et al., 2017) menambahkan ada tiga pergeseran dalam proses pembelajaran akibat perkembangan teknologi komunikasi yaitu: (a) pergeseran dari ruang kelas ke di mana dan kapan saja; (b) pergeseran dari kertas ke online; dan (c) pergeseran fasilitas fsik ke fasilitas jaringan kerja. (Sari, 2017) menyatakan bahwa adanya teknologi informasi ini guru dapat memberikan layanan tanpa harus berhadapan langsung dengan peserta didik. Demikian pula peserta didik dapat memperoleh informasi dalam lingkup yang luas dari berbagai sumber melalui ruang maya dengan menggunakan komputer atau internet.

Penyelenggaraan pembelajaran online membutuhkan Learning Management System (LMS), berfungsi mengatur tatalaksana penyelenggaraan ol-learning (Waryanto, 2006). Seiring dengan kemajuan teknologi informasi, ada banyak jenis LMS yang dapat digunakan, seperti : Moodle, Dokeos, Schoology, Edu, Edmodo, dan masih banyak lagi jenis LMS lainnya. Meskipun demikian yang perlu menjadi pertimbangan dalam pemilihan LMS adalah kemudahan baik dalam hal akses, penggunaan dan pengembangan konten pembelajaran dalam LMS itu sendiri. Dalam penelitian ini, LMS yang digunakan adalah e-lumak berbasis moodel. Hasil Penelitian pada tahun 2020 bahwa Universitas Muhammadiyah Kendari adalah salah satu kampus swasta terbaik se-Sulawesi Tenggara dalam hal pengelolaan dan penggunaan Spada. Hal ini menunjukkan bahwa dosen telah mampu mendesain pembelajaran melalui e-lumak berbasis moodle dengan baik.

Pada Tahun 2020 Universitas Muhammadiyah Kendari mengadakan pelatihan pemanfaatan elumak bagi dosen-dosen agar sistem pembelajaran dapat dipantau secara terpusat tahun ajaran 2020/2021. Laman yang digunakan yaitu http://spada.umkendari.ac.id/. Untuk lebih jelasnya dapat dilihat pada Gambar 1 di bawah ini:

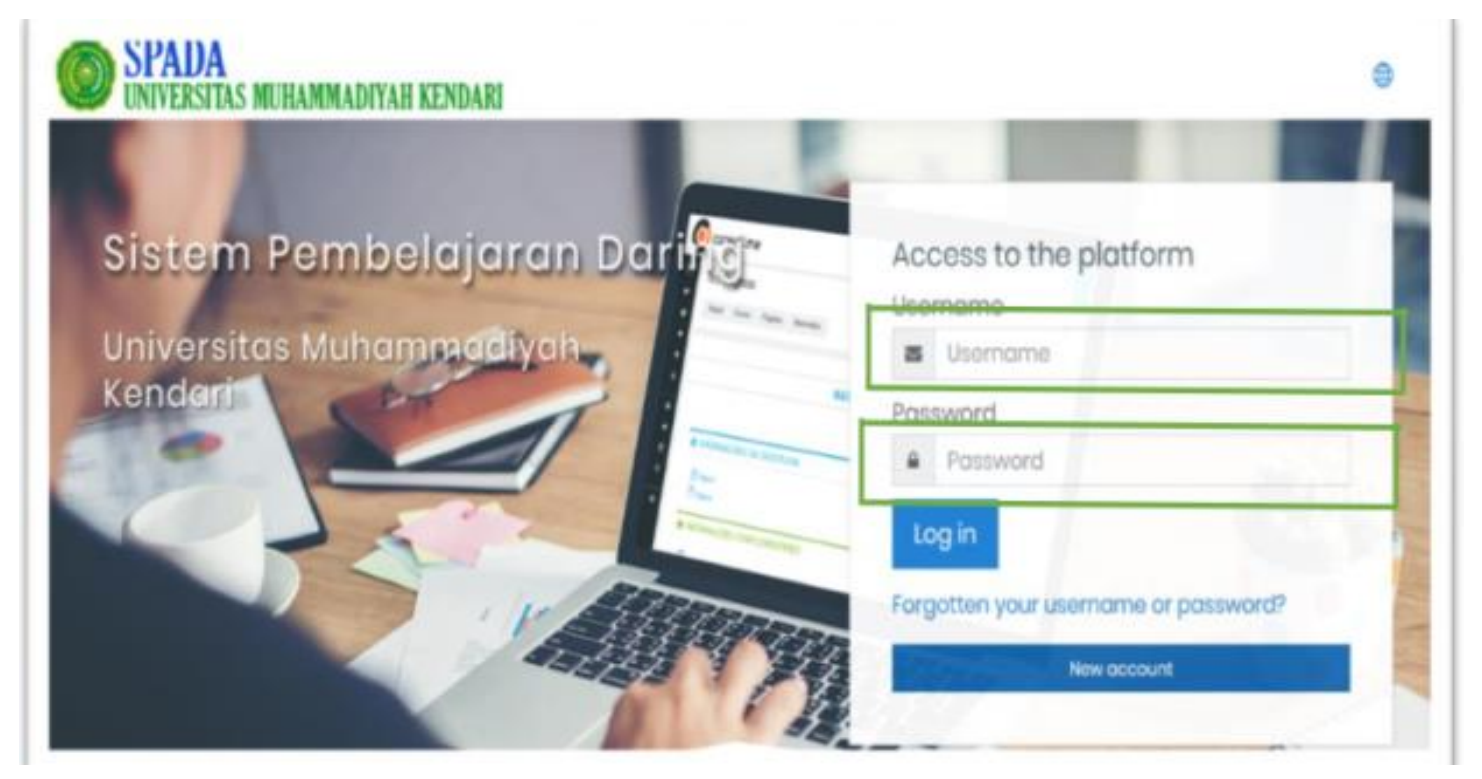

Gambar 1. Tampilan E-lumak

Model pembelajaran berbasis TIK dengan menggunakan e-learning berakibat pada perubahan budaya belajar dalam konteks pembelajarannya. Setidaknya ada empat komponen penting dalam membangun budaya belajar dengan menggunakan model e-learning di sekolah. Pertama, siswa 
dituntut secara mandiri dalam belajar dengan berbagai pendekatan yang sesuai agar siswa mampu mengarahkan, memotivasi, mengatur dirinya sendiri dalam pembelajaran. Kedua, guru mampu mengembangkan pengetahuan dan ketrampilan, memfasilitasi dalam pembelajaran, memahami belajar dan hal-hal yang dibutuhkan dalam pembelajaran. Ketiga tersedianya infrastruktur yang memadai dan yang ke empat administrator yang kreatif serta penyiapan infrastrukur dalam memfasilitasi pembelajaran (Chandrawati, 2010).

Integrasi teknologi yang meningkat dengan cepat telah membawa perubahan yang kuat pada sistem pendidikan dan meningkatkan keterampilan digital baik mahasiswa maupun dosen. Klopfer, E., Osterweil, S., Groff, J., \& Haas, J. melihat bahwa teknologi saat ini lebih dari sekedar untuk hiburan semata. Teknologi juga dapat mempengaruhi cara berpikir, belajar, dan berinteraksi (Irawan, 2018).

Salah satu pemanfaatan internet dalam dunia Pendidikan adalah pembelajaran dalam jaringan (daring). Terdapat berbagai istilah untuk mengemukakan gagasan mengenai pembelajaran online dengan menggunakan internet yaitu on-line learning, e-learning, internet-enabled, virtual learning, virtual classroom atau web based learning (Siahaan, 2003). Penelitian ini menggunakan pembelajaran e-lumak berbasis moddle.

Menurut (Sukardi \& Fahrul Rozi, 2019) menyatakan bahwa moodle menyediakan konten yang dibutuhkan untuk pembelajaran. Hampir semua mahasiswa memiliki laptop/smartphone, sehingga akses terhadap materi belajar semakin mudah dan sangat memungkinan bagi mahasiswa untuk saling berbagi konten pembelajaran melalui perangkat elektronik. Kondisi seperti ini membuat konten pembelajaran semakin lebih cepat didapatkan.

Berdasarkan hasil pengamatan mengenai perkuliahan pada mahasiswa PG-PAUD semester genap tahun ajaran 2019/2020 bahwa sebagian besar mahasiswa merasa berat dengan sistem pembelajaran online. Hal ini disebabkan beberapa hal diantaranya (1) media pembelajaran kurang efektif, (2) jaringan yang kurang memadai, dan (3) kurangnya kemampuan ekonomi mahasiswa.

Faktor ekonomi mahasiswa PG-PAUD Universitas Muhammadiyah Kendari sangat menentukan berlangsungnya proses pembelajaran melalui media e-lumak. (Ellen Margaretha, 2015) menyatakan bahwa tingkat pendapatan orang tua, memberikan kontribusi yang besar sekali demi kelancarnya anak-anaknya dalam menempuh pendidikannya. Dalam pembelajaran ini mengharuskan mahasiswa membeli paket internet. Pembelian paket internet disesuaikan dengan tingkat pendapatan orang tua. Tingkat pendapatan orang tua terbagi atas dua yaitu pendapatan di atas rata-rata dan pendapatan di bawah rata-rata.

Tingkat pendapatan merupakan besarnya penghasilan yang diperoleh oleh satu keluarga (Menhard, 2017). Menurut (Putra \& Baharuddin, 2018) menyatakan tingkat pendapatan orangtua, tingkat pendidikan, sikap keluarga terhadap masalah-masalah sosial, realita kehidupan, dan 
lain-lain. Pada masa pandemic covid-19 tingkat pendapatan orangtua mempengaruhi berlangsungnya proses pembelajaran.

Hasil belajar merupakan salah satu hal yang harus diperhatikan oleh orang tua. Ada beberapa faktor yang dapat mempengaruhi pencapaian hasil belajar anak (Darnis, 2015). Faktor-faktor yang mempengaruhi hasil belajar mahasiswa yaitu, faktor Intern dan faktor ekstern. Faktor intern adalah faktor-faktor yang berasal dari dalam diri seseorang yang dapat mempengaruhi prestasi belajarnya. Diantara faktor-faktor intern yang dapat mempengaruhi hasil belajar seseorang antara lain adalah kecerdasan/intelegensi, bakat, minat, dan motivasi. Sedangkan faktor ekstern adalah faktor-faktor yang dapat mempengaruhi hasil belajar seseorang yang sifatnya berasal dari luar diri seseorang tersebut seperti penggunaan media pembelajaran oleh dosen.

Berdasarkan permasalahan di atas maka peneliti tertarik untuk melaksanakan penelitian pada mahasiswa PG-PAUD Universitas Muhammadiyah Kendari dengan judul "efektivitas media Pembelajaran e-lumak berbasis moodle dan tingkat pendapatan orang tua terhadap hasil Belajar mahasiswa PG-PAUD Universitas Muhammadiyah Kendari di masa pandemi Covid-19”.

\section{METODE}

Penelitian ini dilaksanakan di Universitas Muhammadiyah Kendari Fakultas Keguruan dan Ilmu Pendidikan Program Studi Pendidikan Guru Pendidikan Anak Usia Dini (PG-PAUD). Sedangkan waktu penelitian akan dilaksanakan pada semester ganjil tahun pelajaran 2020/2021.

Populasi dalam penelitian ini adalah seluruh mahasiswa PG-PAUD Semester V di Universitas Muhammadiyah kendari yang terdiri dari 4 kelas paralel dengan masing-masing kelas berjumlah 15 mahasiswa sehingga jumlah keseluruhan 60 orang. Berdasarkan tingkat pendapatan orang tua, populasi dibedakan atas dua kelompok, yaitu mahasiswa yang tingkat pendapatan orang tua level tinggi di atas rata-rata dan mahasiswa yang tingkat pendapatan orang tua dibawah rata-rata. Sampel dalam penelitian dapat digambarkan sebagai berikut:

Tabel 1. Sampel Mahasiswa PG-PAUD Semester V Tahun Ajaran 2020/2021

\begin{tabular}{|c|c|c|c|}
\hline \multirow{2}{*}{$\mathbf{A}$} & \multicolumn{2}{|c|}{$\mathbf{B}$} & \multirow{2}{*}{ Jumlah } \\
\cline { 2 - 4 } & $\mathbf{B = 1}$ & $\mathbf{B = 2}$ & \\
\hline $\mathbf{A = 1}$ & 15 & 15 & 30 \\
\hline $\mathbf{A = \mathbf { 2 }}$ & 15 & 15 & 30 \\
\hline Jumlah & 30 & 30 & 60 \\
\hline
\end{tabular}

Keterangan:

$\mathrm{A}=$ Media pembelajaran, dengan $\mathrm{A}=1$ media pembelajaran e-lumak berbasis moodle, dan $\mathrm{A}=2$ pembelajaran dengan menggunakan media google classroom.

B = Tingkat Pendapatan Orang Tua, dengan B = 1 mahasiswa yang pendapatan orang tua di atas ratarata dan $\mathrm{B}=21$ mahasiswa yang pendapatan orang tua di bawah rata-rata.

Penelitian ini menggunakan Randomized Control Group Desain, dimana populasi dibagi atas dua kelompok secara random, yaitu kelompok pertama sebagai unit eksperimen untuk perlakuan dan 
kelompok kedua sebagai unit kontrol untuk pembanding (Maonde, 2011), dengan desain dapat dilihat pada Tabel 2 sebagai berikut:

Tabel 2. Desain Penelitian

\begin{tabular}{|l|l|l|l|}
\hline $\mathrm{R}$ & $\mathrm{E}$ & $\mathrm{T}$ & $\mathrm{O}_{1}$ \\
\hline $\mathrm{R}$ & $\mathrm{K}$ & $\cdot$ & $\mathrm{O}_{2}$ \\
\hline
\end{tabular}

Keterangan:

R: Random, random (yaitu random berdasarkan: (i) random kelas untuk menentukan banyaknya sampel (ii) random kelas untuk menentukan kelas eksperimen dan (iii) random individu sebagai unit analisis)

\section{K: Kontrol}

E: Eksperimen, eksperimen (sebagai kelas eksperimen pada model pembelajaran (faktor A) adalah $\mathrm{A}=1$ yaitu media pembelajaran e-lumak berbasis moodle, $\mathrm{A}=2$ yaitu pembelajaran dengan menggunakan GS, sedangkan pada tingkat pendapatan orang tua (faktor B) adalah $\mathrm{B}=1$ pendapatan orang tua yaitu di atas rata-rata dan $\mathrm{B}=2$ yaitu pendapatan orang tua di bawah ratarata

T: True eksperimen

$\mathrm{O}_{\mathrm{k}}$ : Observasi, $\mathrm{k}=1,2\left(\mathrm{O}_{1}\right.$ tes yang diberikan dengan pada kelas eksperimen dan $\mathrm{O}_{2}=$ tes yang diberikan pada kelas kontrol)

Teknik pengumpulan dalam penelitian ini menggunakan pemberian tes, angket tingkat pendapatan orang tua, dan dokumentasi. Instrumen yang diberikan dalam penelitian ini adalah melalui uji validitas dan reliabilitas.

Teknik analisis data penelitian berupa analisis deskriptif dan analisis inferensial (Sugiyono, 2012). Analisis deskriptif dimaksudkan untuk mendeskripsikan karakteristik responden varibel bebas model pembelajaran berbasis e-lumak dan tingkat pendapatan orang tua terhadap variabel terikat melalui skor rata-rata (mean) dan standar deviasi.

Analisis inferensial dimaksudkan untuk menguji hipotesis pengaruh perlakuan antara variabel bebas terhadap variabel terikat, dengan menggunakan analisis varian yang terdiri dari:

1. Model umum analisis dan hipotesis antara Media pembelajaran dan tingkat pendapatan orang tua terhadap rerata hasil belajar statistik pendidikan adalah sebagai berikut:

$$
\mathrm{Y}_{\mathrm{ijk}}=\mu+\mathrm{Ai}+\mathrm{Bj}+(\mathrm{AB}) \mathrm{ij}+\varepsilon_{\mathrm{ijk}}
$$

Dimana:

$\mathrm{Y}_{\mathrm{ijk}} \quad=$ pengamatan ke-k dalam kelompok ke-i dan ke-j dari media pembelajaran dan tingkat pendapatan orang tua untuk variabel ke-i dan ke-j.

$\mu \quad=$ parameter rerata $Y_{\mathrm{ijk}}$ dalam kelompok ke-i dan ke-j dari Media pembelajaran dan tingkat pendapatan orang tua untuk variabel ke-i dan ke-j.

$\mathrm{Ai} \quad=$ pengamatan ke-i dari media pembelajaran.

$\mathrm{Bj} \quad=$ pengamatan ke-j dari tingkat pendapatan orang tua

$(\mathrm{AB}) \mathrm{ij}=$ pengamatan ke-i dan ke-j dari media pembelajaran dan tingkat pendapatan orang tua yang juga merupakan faktor interaksi 
$\varepsilon_{\mathrm{ijk}}=$ suku kesalahan random dari model dengan asumsi $\varepsilon_{\mathrm{ijk}} \approx N I I\left(0, \delta^{2}\right)$, dengan $\mathrm{i}=1,2, ; \mathrm{j}=$ 1,2 dan $\mathrm{k}=1,2,3, \ldots, \mathrm{n}$.

(Agung, 2012)

Berdasarkan model (1), hipotesis yang diperlukan adalah:

$\mathrm{H}_{0}: \mathrm{A}_{\mathrm{i}}=\mathrm{B}_{\mathrm{j}}=(\mathrm{AB})_{\mathrm{ij}}=0$, vs $\mathrm{H}_{1}$ : Bukan $\mathrm{H}_{0}$ (Minimal ada satu parameter yang $\neq 0$ )

Hipotesis tersebut dipakai untuk menguji pernyataan hipotesis model pembelajaran berbasis e-lumak dan tingkat pendapatan orang tua termasuk interaksinya secara simultan mempunyai pengaruh yang signifikan terhadap rerata hasil belajar statistik pendidikan.

Uji hipotesis secara bersama-sama menggunakan statistik uji F, dengan syarat menolak Ho jika $F_{\text {hit }}>F_{\text {tab. }}$.

2. Analisis Perbedaan

Analisis perbedaan dalam penelitian ini terdiri atas dua hipotesis sebagai berikut:

a. perbedaan rerata hasil belajar statistik pendidikan untuk mahasiswa yang diajar dengan media pembelajaran e-lumak berbasis moodle dibanding mahasiswa yang diajar dengan media pembelajaran berbasis GC khusus untuk mahasiswa yang tingkat pendapatan orang tua di atas rata-rata.

b. perbedaan rerata hasil belajar statistik Pendidikan untuk mahasiswa yang diajar dengan media pembelajaran e-lumak berbasis moodle dibanding mahasiswa yang diajar dengan media pembelajaran berbasis GC khusus untuk mahasiswa yang tingkat pendapatan orang tua di bawah rata-rata.

Uji hipotesis secara parsial menggunakan statistik uji t, dengan syarat menolak Ho jika $t_{\text {hit }}$ $>t_{\text {tab. }}$ Jika menggunakan program siap pakai dalam hal ini SPSS, H0 ditolak dengan syarat $p$-value $<\alpha=0,05$ (Usman, 2013).

\section{HASIL DAN DISKUSI}

Analisis deskriptif hasil belajar matematika dimaksudkan untuk mendekripsikan karakteristik responden melalui skor rata-rata, modus, median, dan standar deviasi dari masing-masing sel yang dibentuk oleh kombinasi antara faktor model pembelajaran berbasis e-lumak dan faktor tingkat pendapatan orang tua, A1B1 dan A1B2 adalah kelompok mahasiswa yang diajar dengan menggunakan media pembelajaran e-lumak berbasis moodle untuk mahasiswa yang tingkat pendapatan orang tua di atas rata-rata dan di bawah rata-rata, A2B1 dan A2B2 adalah kelompok mahasiswa yang diajar dengan menggunakan media pembelajaran berbasis google classroom untuk untuk mahasiswa yang tingkat pendapatan orang tua di atas rata-rata dan di bawah rata-rata.

Analisis deskriptif juga dilakukan untuk masing-masing sel yang dibentuk oleh kombinasi antara faktor $\left(\mathrm{A}_{\mathrm{i}}\right)$ model pembelajaran berbasis e-lumak dan faktor $\left(\mathrm{B}_{\mathrm{j}}\right)$ tingkat pendapatan orang tua. Dengan menggunakan program SPSS diperoleh hasil analisis sebagaimana ditunjukan dalam Tabel 3 berikut: 
Tabel 3. Analisis Deskriptif Data Hasil Belajar Statistik Pendidikan Menurut Kombinasi Antara Faktor Media Pembelajaran E-lumak Berbasis Moodle $\left(\mathrm{A}_{\mathrm{i}}\right)$ dan Tingkat Pendapatan Orang Tua $\left(\mathrm{B}_{\mathrm{j}}\right)$

\begin{tabular}{|c|c|c|}
\hline Kelompok & Rata-rata (mean) & Standar Deviasi \\
\hline $\mathrm{A}=1, \mathrm{~B}=1$ & 84,42 & 3,052 \\
\hline $\mathrm{A}=1, \mathrm{~B}=2$ & 81,78 & 5,297 \\
\hline Total & 83,10 & 4,45 \\
\hline $\mathrm{A}=2, \mathrm{~B}=1$ & 75,35 & 6,784 \\
\hline $\mathrm{A}=2, \mathrm{~B}=2$ & 73,78 & 5,193 \\
\hline Total & 78,83 & 6,78 \\
\hline
\end{tabular}

Sumber: Data Primer Diolah Dengan SPSS/PC ver. 16.00

Berdasarkan hasil analisis Tabel 3 di atas dapat dikemukakan bahwa secara empiris ternyata hasil belajar statistik pendidikan mahasiswa untuk kelas yang diajar dengan media pembelajaran e-lumak berbasis moodle mempunyai rata-rata 83,10 dan standar deviasi 4,45. Sedangkan hasil belajar statistik pendidikan mahasiswa yang diajar dengan menggunakan media pembelajaran berbasis GC mempunyai rata-rata sebesar 78,83 dan standar deviasi sebesar 6,78.

Perbadingan rata-rata (mean) dan standar deviasi hasil belajar statistik pendidikan mahasiswa yang diajar dengan menggunakan media pembelajaran e-lumak berbasis moodle dan kelompok mahasiswa yang diajar dengan menggunakan media pembelajaran berbasis GC disajikan dalam diagram batang pada Gambar 2 di bawah ini:

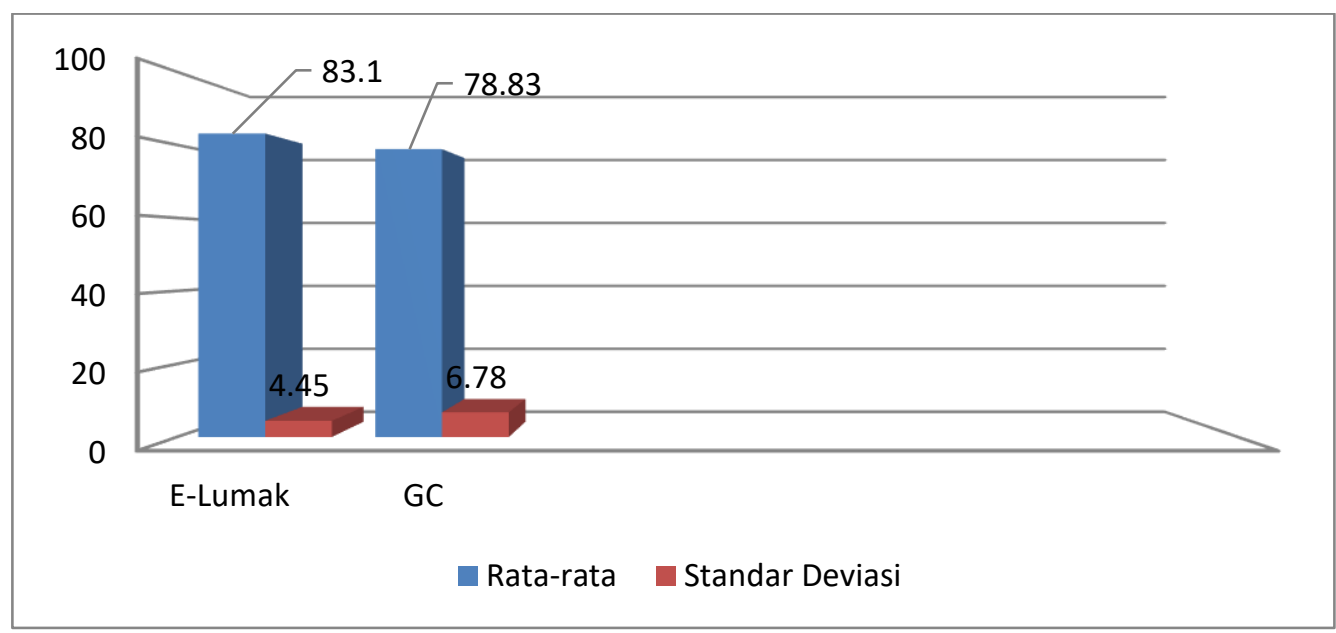

Gambar 2. Perbandingan Rata-rata dan Standar Deviasi Hasil Belajar Mahasiswa pada Kelompok E-lumak dan kelompok GC

Berdasarkan hasil analisis Tabel 3 di atas juga dapat dikemukakan bahwa:

a. Secara empiris ternyata untuk kelas yang diajar dengan media pembelajaran e-lumak berbasis moodle dan mahasiswa yang memiliki tingkat pendapat orangtua di atas rata-rata mempunyai rata-rata 84,42. Untuk kelas yang diajar dengan media pembelajaran e-lumak berbasis moodle dan mahasiswa yang memiliki tingkat pendapat orangtua di bawah rata-rata mempunyai rata-rata 
81,78. untuk kelas yang diajar dengan media pembelajaran GC dan mahasiswa yang memiliki tingkat pendapat orangtua di atas rata-rata mempunyai rata-rata 75,35. Sedangkan untuk kelas yang diajar dengan media pembelajaran berbasis GC dan mahasiswa yang memiliki tingkat pendapat orangtua di bawah rata-rata mempunyai rata-rata 73,78.

b. Secara empiris ternyata rata-rata hasil belajar statistik pendidikan antara kelompok mahasiswa yang yang diajar dengan menggunakan media pembelajaran e-lumak berbasis moodle dan mempunyai tingkat pendapatan orangtua di atas rata-rata (A1B1) lebih tinggi bila dibandingkan dengan kelompok mahasiswa yang yang diajar dengan menggunakan media pembelajaran elumak berbasis moodle dan mempunyai tingkat pendapatan orangtua di bawah rata-rata (A1B2).

c. Secara empiris ternyata rata-rata hasil belajar statistik pendidikan antara kelompok mahasiswa yang yang diajar dengan menggunakan media pembelajaran berbasis GC dan mempunyai tingkat pendapatan orangtua di atas rata-rata (A2B1) lebih tinggi bila dibandingkan dengan kelompok mahasiswa yang yang diajar dengan menggunakan media pembelajaran berbasis GC dan mempunyai tingkat pendapatan orangtua di bawah rata-rata (A1B2).

Perbadingan rata-rata dan standar deviasi hasil belajar mahasiswa yang diajar dengan e-lumak dan GC baik mahasiswa yang memiliki tingkat pendapatan orangtua di atas rata-rata maupun di bawah rata-rata. Untuk lebih jelasnya dapat dilihat pada Gambar 3 di bawah ini:

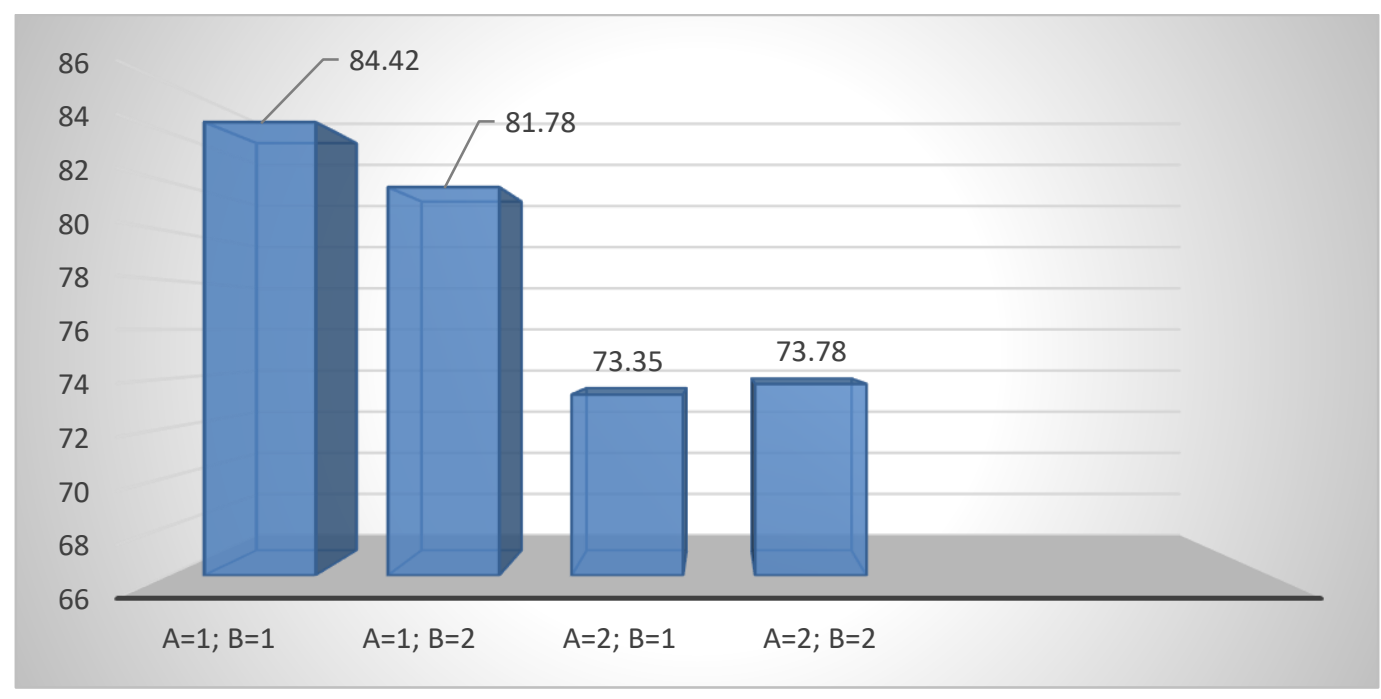

Gambar 3. Perbandingan Rata-rata HBM pada Kelompok E-lumak dan kelompok GC ditinjau dari tingkat Pendapatan Orangtua

Sebelum dilakukan analisis inferensial terlebih dahulu melakukan uji normalitas dan homogenitas data. Uji normalitas dilakukan untuk melihat apakah data yang kita peroleh berdistribusi normal atau mengikuti kurva normal atau tidak, sedangkan uji homogenitas data dilakukan untuk melihat apakah data yang kita peroleh mengikuti varians yang sama atau tidak.

Data dalam penelitian ini diasumsikan bahwa suku kesalahan random model linear univariat mempunyai distribusi normal. Hal ini didukung oleh teorema limit sentral yang menyatakan bahwa 
ruang sampel yang merupakan himpunan semua nilai rerata sampel yang mungkin diobservasi mempunyai pendekatan distribusi normal. Pada umumnya, teorema limit sentral telah ditetapkan untuk ukuran sampel minimal $n=30$ (Agung, 2012).

Uji homogenitas dimaksudkan untuk mengetahui apakah variasi data variabel terikat homogen sebagai akibat dari pengelompokkan data variabel bebas. Hasil perhitungan homogenitas dengan menggunakan uji Lavene diperoleh nilai-p=0,072 $>\propto=0,05$ atau $\mathrm{F}_{\text {hitung }}=2,456<\mathrm{F}_{\text {tabel }}=2,77$. Karena nilai-p $>\propto=0,05$ dan $\mathrm{F}_{\text {hitung }}<\mathrm{F}_{\text {tabel }}$ maka $\mathrm{H}_{0}$ ditolak. Dengan ditolaknya $\mathrm{H}_{0}$ maka dapat disimpulkan bahwa data yang dipakai mendukung kebenaran asumsi suku kesalahan random mempunyai varian yang tidak sama atau heterogen.

Analisis inferensial diperlukan untuk menguji sejumlah hipotesis pengaruh model pembelajaran berbasis e-lumak dan tingkat pendapatan orang tua terhadap hasil belajar statistik pendidikan mahasiswa, serta perbedaan rerata hasil belajar statistik pendidikan menurut $A_{i}$ dan $B_{j}$, sebagai berikut:

Analisis pengaruh Media Pembelajaran E-lumak Berbasis Moodle $\left(A_{i}\right)$ dan Tingkat Pendapatan Orang Tua $\left(B_{j}\right)$ serta Interaksinya secara Bersama-sama Terhadap Hasil Belajar Statistik Pendidikan

Analisis pengaruh model pembelajaran berbasis e-lumak $\left(A_{i}\right)$ dan tingkat pendapatan orangtua $\left(B_{j}\right)$ serta interaksinya secara bersama-sama terhadap hasil belajar matematika menggunakan statistik uji-F, dengan pernyataan hipotesis "media pembelajaran e-lumak berbasis moodle dan tingkat Pendapatan Orangtua termasuk interaksinya secara bersama-sama terhadap hasil belajar statistik Pendidikan mempunyai pengaruh yang signifikan".

Pernyataan di atas dirumuskan dalam hipotesis statistik sebagai berikut:

$\mathrm{H}_{0}: \mathrm{A}_{\mathrm{i}}=\mathrm{B}_{\mathrm{j}}=(\mathrm{AB})_{\mathrm{ij}}=0$ vs $\mathrm{H}_{1}$ : Bukan $\mathrm{H}_{0}$ (Minimal ada satu parameter yang $\neq 0$ )

Dengan memperhatikan statistik $\mathrm{F}$, jika $\mathrm{F}_{\text {hitung }} \geq \mathrm{F}_{\text {tabel }}$ atau p-value $<\alpha=0,05$, maka $\mathrm{H}_{0}$ ditolak. Hasil perhitungan selengkapnya, dapat dilihat pada Tabel 4 di bawah ini:

Tabel 4. Hasil Analisis Rerata Hasil Belajar Menurut $A_{i}$ dan $B_{j}$

\begin{tabular}{|l|r|c|r|r|r|}
\hline Source & $\begin{array}{c}\text { Type III Sum of } \\
\text { Squares }\end{array}$ & Df & Mean Square & \multicolumn{1}{c|}{$\boldsymbol{F}$} & \multicolumn{1}{c|}{ Sig. } \\
\hline Corrected Model & $1163.427^{\mathrm{a}}$ & 3 & 387.809 & 14.055 & .000 \\
\hline Intercept & 372873.783 & 1 & 372873.783 & $1.351 \mathrm{E} 4$ & .000 \\
\hline A & 1092.352 & 1 & 1092.352 & 39.589 & .000 \\
\hline B & 66.803 & 1 & 66.803 & 2.421 & .125 \\
\hline A * B & 4.272 & 1 & 4.272 & .155 & .695 \\
\hline Error & 1545.185 & 56 & 27.593 & & \\
\hline Total & 375582.395 & 60 & & & \\
\hline
\end{tabular}

Sumber: Data Primer Diolah Dengan SPSS/PC ver. 16.00

Berdasarkan hasil analisis pada Tabel 4 diperoleh $F_{\text {hitung }}=14,055$ df 3/56 sehingga $F_{\text {tabel }}=2,77$ atau dengan $p$-value $=0,000<\alpha=0,05$. Dengan demikian, maka $\mathrm{H}_{0}$ ditolak. Ditolaknya $\mathrm{H}_{0}$ dapat 
disimpulkan bahwa media pembelajaran e-lumak berbasis moodle dan tingkat pendapatan orangtua termasuk interaksinya secara bersama-sama mempunyai pengaruh yang signifikan terhadap hasil belajar statistik pendidikan.

\section{Analisis Data Perbedaan Dua Rata-Rata Hasil Belajar dengan Syarat Tingkat Pendapatan Orangtua}

Hipotesis kedua berbunyi "terdapat perbedaan rerata hasil belajar statistik pendidikan untuk mahasiswa yang diajar dengan media pembelajaran e-lumak berbasis moodle dibanding mahasiswa yang diajar dengan media pembelajaran berbasis google classroom khusus untuk mahasiswa yang tingkat pendapatan orang tua di atas rata-rata". Hipotesis ini diuji menggunakan rumus uji t dua sampel. Untuk lebih jelasnya dapat disajikan dalam Tabel 5 di bawah ini:

Tabel 5. Uji perbedaan Dua Rata-rata Data Kemampuan Hasil Belajar kelompok e-lumak dan Kelompok GC Untuk Tingkat Pendapatan Orangtua di Atas Rata-rata

\begin{tabular}{|c|c|c|c|}
\hline $\mathbf{t}$ & Df & Sig. (2-tailed) & Keterangan \\
\hline 4.72 & 28 & .000 & Ho ditolak \\
\hline
\end{tabular}

Sumber: Data Primer Diolah Dengan SPSS/PC ver. 16.00

Dari hasil analisis pada Tabel 5 di atas, terlihat pada uji Levene nilai sig. $=0,005$ lebih kecil dari taraf signifikansi 0,05 maka kedua kelompok data eksperimen dan kelompok kontrol mahasiswa yang memiliki tingkat pendapatan orangtua di atas rata-rata mempunyai varians yang tidak homogen sehingga uji hipotesis perbedaan yang digunakan adalah uji $\mathrm{t}^{*}$. Pada Tabel 5.4 diperoleh nilai $\mathrm{t}$ dengan degree of fredom atau $\mathrm{df}=28$ sebesar 4,72 dengan $\mathrm{t}_{\text {tebel }}(\alpha=0,05,19,4)=2,086$ dan Sig. (2-tailed) adalah 0,000 . Nilai $t_{\text {hitung }}$ lebih besar dari nilai $t_{\text {tabel }}$ atau nilai signifikansi ini lebih kecil dari taraf signifikansi 0,05 yang ditetapkan, sehingga hipotesis nol ditolak. Dengan demikian, terdapat perbedaan rerata hasil belajar statistik pendidikan untuk mahasiswa yang diajar dengan media pembelajaran e-lumak berbasis moodle dibanding mahasiswa yang diajar dengan media pembelajaran berbasis google classroom khusus untuk mahasiswa yang tingkat pendapatan orang tua di atas ratarata.

Hipotesis ketiga berbunyi "terdapat perbedaan rerata hasil belajar statistik pendidikan untuk mahasiswa yang diajar dengan media pembelajaran e-lumak berbasis moodle dibanding mahasiswa yang diajar dengan media pembelajaran berbasis google classroom khusus untuk mahasiswa yang tingkat pendapatan orang tua di bawah rata-rata”. Hipotesis ini diuji menggunakan rumus uji $\mathrm{t}$ dua sampel. Untuk lebih jelasnya dapat disajikan dalam Tabel 6 di bawah ini:

Tabel 6. Uji perbedaan Dua Rata-rata Data Kemampuan Hasil Belajar Kelompok E-lumak dan Kelompok GC Untuk Tingkat Pendapatan Orangtua di Bawah Rata-rata

\begin{tabular}{|c|c|c|c|}
\hline $\mathrm{T}$ & $\mathrm{Df}$ & Sig. (2-tailed) & Keterangan \\
\hline 4.177 & 28 & .000 & Ho ditolak \\
\hline
\end{tabular}

Sumber: Data Primer Diolah Dengan SPSS/PC ver. 16.00 
Dari hasil analisis pada Tabel 6 di atas, terlihat pada uji Levene nilai sig. $=0,967$ lebih besar dari taraf signifikansi 0,05 maka kedua kelompok data eksperimen dan kelompok kontrol mahasiswa yang memiliki tingkat pendapatan orangtua di bawah rata-rata mempunyai varians yang homogen sehingga uji hipotesis perbedaan yang digunakan adalah uji t. Pada Tabel 5 diperoleh nilai $\mathrm{t}$ dengan degree of fredom atau $\mathrm{df}=28$ sebesar 4,177 dengan $\mathrm{t}_{\text {tebel }}(\alpha=0,05,28)=2,086$ dan Sig. (2-tailed) adalah 0,000 . Nilai $t_{\text {hitung }}$ lebih besar dari nilai $t_{\text {tabel }}$ atau nilai signifikansi ini lebih kecil dari taraf signifikansi 0,05 yang ditetapkan, sehingga hipotesis nol ditolak. Dengan demikian, terdapat perbedaan rerata hasil belajar statistik pendidikan untuk mahasiswa yang diajar dengan media pembelajaran e-lumak berbasis moodle dibandig mahasiswa yang diajar dengan media pembelajaran berbasis google classroom khusus untuk mahasiswa yang tingkat pendapatan orang tua di bawah rata-rata.

Hasil analisis data baik dari analisis deskriptif maupun analisis inferensial menunjukkan bahwa terdapat pengaruh pembelajaran berbasis e-lumak terhadap hasil belajar statistik pendidikan mahasiswa. Pada model ini, terdapat satu hipotesis yang diuji yaitu hipotesis secara simultan atau bersama-sama. Secara simultan media pembelajaran e-lumak berbasis moodle dan tingkat pendapatan orangtua termasuk interaksinya mempunyai pengaruh yang signifikan terhadap hasil belajar statistik pendidikan walaupun faktor media pembelajaran e-lumak berbasis moodle yang dilihat pada baris A pada Tabel 4 mempunyai pengaruh signifikan terhadap hasil belajar statistik pendidikan mahasiswa sedangkan faktor tingkat pendapatan orangtua yang dilihat pada baris B pada Tabel 4 tidak mempunyai pengaruh yang signifikan terhadap hasil belajar statistik Pendidikan mahasiswa.

Hal ini sejalan dengan hasil penelitian yang dilakukan oleh (Karwati, 2014) bahwa pembelajaran elektronik berada dalam kategori yang tinggi, sementara kualitas pembelajaran berada dalam kategori cukup. Selain itu, diperoleh temuan bahwa pembelajaran elektronik memiliki pengaruh yang positif dan signifikan terhadap kualitas pembelajaran. (Aurora \& Effendi, 2019) menyatakan bahwa terdapat pengaruh antara penggunaan media pembelajaran E-Learning terhadap motivasi belajar mahasiswa. Di samping itu, (Sandi, 2005) menyetakan bahwa hasil belajar kimia siswa yang mengikuti blended learning lebih tinggi daripada hasil belajar siswa yang mengikuti pembelajaran langsung.

Di samping itu, hipotesis yang berbunyi terdapat perbedaan rerata hasil belajar statistik pendidikan untuk mahasiswa yang diajar dengan media pembelajaran e-lumak berbasis moodle dibanding mahasiswa yang diajar dengan media pembelajaran berbasis google classroom khusus untuk mahasiswa yang tingkat pendapatan orang tua di atas maupun di bawah rata-rata. Penyebab adanya perbedaan hasil belajar statistik pendidikan kedua model pembelajaran adalah karena mahasiswa senang dan aktif dalam proses pembelajaran dengan menggunakan media pembelajaran elumak berbasis moodle. Mahsiswa sangat antusias dengan hal baru yang dilakukan oleh peneliti. Sedangkan mahasiswa yang diajar dengan menggunakan google classroom tidak aktif dan tidak antusias. Hal ini didukung dengan pendapat (Putra \& Baharuddin, 2018) yang menyatakan bahwa 
tingkat pendapatan orangtua berpengaruh positif dan signifikan terhadap nilai belajar siswa.

Ketidak aktifan mahasiswa pada kelompok yang diajar dengan menggunakan google classroom disebabkan oleh fitur-fitur yang ada pada google classroom sangat tidak lengkap. Pada google classroom mahasiswa dan dosen hanya menggunakan chat dalam proses pembelajaran. Dosen mengirim materi yang akan dibahas dan mahasiswa membaca materi tersebut. Sedangkan pada elumak banyak fitur yang disiapkan diantaranya forum diskusi, video converence (bigblubutten) dan masih banyak fitur-fitur yang lainnya. Untuk lebih jelasnya dapat dilihat pada Gambar 3 di bawah ini:
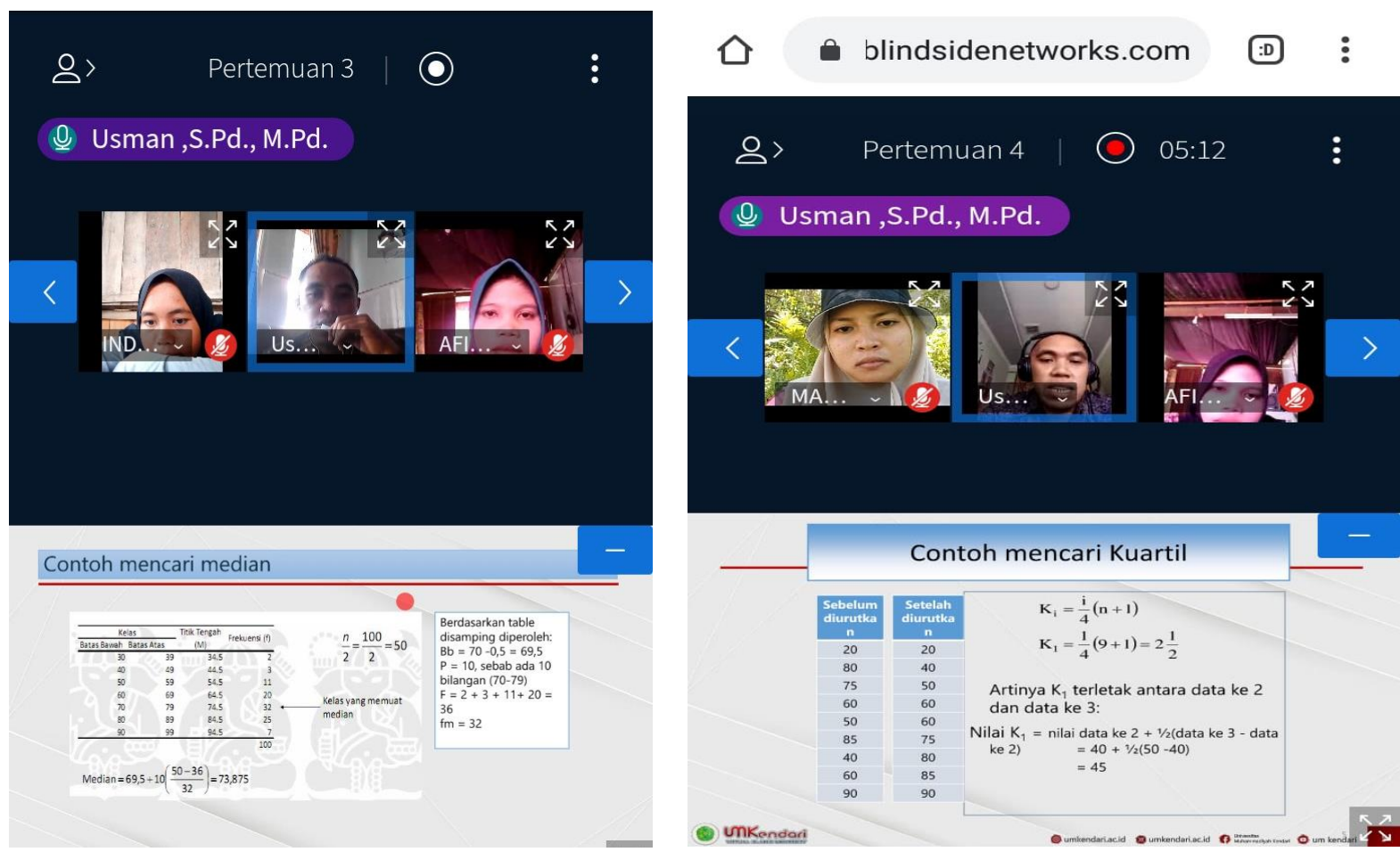

Gambar 3: Aktivitas dalam pembelajaran dengan menggunakan Media E-lumak

Pada pembelajaran dengan menggunakan media elumak berbasis moodle dapat meningkatkan minat dan motivasi belajar mahasiswa. Strategi yang digunakan dosen adalah dengan merekam seluruh aktivitas pembelajaran mulai pembuka sampai dengan penutup. Media pembelajaran e-lumak berbasis moodle menyediakan berbagai aktivitas pembelajaran diantaranya assignment, bigbluebuttonbn, chat, choice, database, external tool, feedback, forum, glossary, lesson, quiz, scorm package, survey, wiki, dan workshop. Di samping itu, juga menyediakan sumber belajar diantaranya book, file, folder, IMS content package, label, page, dan URL.

Hal ini sejalan dengan (Numiek Sulistyo Hanum, 2011) menyatakan bahwa Pemanfaatan $\boldsymbol{e}$ learning dalam proses pembelajaran diharapkan bisa meningkatkan motivasi dan hasil belajar peserta didik. Selain itu, alur proses pembelajaran tidak harus berasal dari pendidik menuju peserta didik. Peserta didik bisa juga saling belajar dari sesama peserta didik lainnya. Selain itu, (Herayanti et al., 2017) menyatakan bahwa pengembangan media moodle dinyatakan 
'layak' untuk digunakan demi mendukung proses pembelajaran dalam perkuliahan. Mahasiswa memberikan respon yang positif serta dapat meningkatkan motivasi belajar mereka.

\section{KESIMPULAN}

Berdasarkan hasil dan pembahasan maka kesimpulan dalam penelitian ini adalah sebagai berikut: (1) Hasil belajar mahasiswa yang diajar dengan media pembelajaran elumak berbasis moodle dan mahasiswa yang memiliki tingkat pendapat orangtua di atas rata-rata mempunyai rata-rata 84,42. Untuk kelas yang diajar dengan media pembelajaran e-lumak berbasis moodle dan mahasiswa yang memiliki tingkat pendapat orangtua di bawah rata-rata mempunyai rata-rata 81,78. (2) Hasil belajar statistik pendidikan mahasiswa yang diajar dengan media pembelajaran GC dan mahasiswa yang memiliki tingkat pendapat orangtua di atas rata-rata mempunyai rata-rata 75,35 . Sedangkan untuk kelas yang diajar dengan model pembelajaran berbasis google classroom dan mahasiswa yang memiliki tingkat pendapat orangtua di bawah rata-rata mempunyai rata-rata 73,78. (3) Terdapat pengaruh media pembelajaran e-lumak berbasis moodle dan tingkat pendapatan orang tua termasuk interaksinya secara simultan terhadap rerata hasil belajar mahasiswa PG-PAUD Universitas Muhammadiyah Kendari di masa pandemi covid-19. (4) Terdapat perbedaan rerata hasil belajar untuk mahasiswa yang diajar dengan media pembelajaran e-lumak berbasis moodle dibanding mahasiswa yang diajar dengan model pembelajaran berbasis google classroom khusus untuk mahasiswa yang tingkat pendapatan orang tua di atas rata-rata. (5) Terdapat perbedaan rerata hasil belajar untuk mahasiswa yang diajar dengan media pembelajaran e-lumak berbasis moodle dibanding mahasiswa yang diajar dengan media pembelajaran berbasis google classroom khusus untuk mahasiswa yang tingkat pendapatan orang tua di bawah rata-rata

\section{UCAPAN TERIMAKASIH}

Berdasarkan hasil penelitian ini, maka ada beberapa saran untuk meningkatkan kualitas pembelajaran dosen di masa pandemi covid-19 yaitu dengan memanfaatkan media pembelajaran elumak berbasis moodle. Model pembelajaran ini sangat efektif digunakan sebab mengandng beberapa platform yang sangat lengkap. Sebagai tenaga pendidikan dapat menggunakan media pembelajaran elumak berbasis moddle dalam pembelajaran di masa pandemic covid-19 khususnya dosen-dosen Universitas Muhammadiyah Kendari.

Penelitian ini didanai pada program Hibah RisetMu Batch 4 Majelis Diktilitbang Pimpinan Pusat Muhammadiyah. Oleh karena itu, ucapan terimakasih kepada program hibah covid-19 riset muhammadiyah untuk anggaran 2020. Terimakasih juga kepada Universitas Muhammadiyah Kendari yang telah banyak mendukung dalam melaksanakan hibah penelitian ini. 


\section{REFERENSI}

Agung, I. G. N. (2012). Statistika Penerapan Model Rerata-Sel Multivariat dan Model Ekonometri dengan SPSS. PT. Raja Grafindo Persada.

Al-Fatih, S., Ahsany, F., \& Alamsyah, A. F. (2020). Legal Protection of Labor Rights During the Coronavirus Disease 2019 (Covid-19) Pandemic. Jurnal Pembaharuan Hukum, 7(2), 100. https://doi.org/10.26532/jph.v7i2.10975

Aurora, A., \& Effendi, H. (2019). Pengaruh Penggunaan Media Pembelajaran E-learning terhadap Motivasi Belajar Mahasiswa di Universitas Negeri Padang. Jurnal Teknik Elektro Vokasional, 5(2), 11-16. http://ejournal.unp.ac.id/index.php/jtev/index

Chandrawati, S. R. (2010). Pemanfaatan E-Learning Dalam Pembelajaran. Jurnal Cakrawala Pendidikan, 8(2), 101-117. https://journal.uny.ac.id/index.php/cp

Darnis, A. (2015). Pengaruh Perhatian Dan Tingkat Pendapatan Orang Tua Terhadap Hasil Belajar Ekonomi Siswa Kelas Xi Di Sma Negeri 12 Sijunjung. Economica, 2(1), 11-21. https://doi.org/10.22202/economica.2013.v2.i1.212

Ellen Margaretha. (2015). Pengaruh Tingkat Pendidikan, Tingkat Pendapatan dan Pola Asuh Orang Tua Terhadap Prestasi Belajar IPS Siswa. Jurnal Penelitian Dan Pendidikan IPS, 9(3), 12611267.

Herayanti, L., Habibi, H., \& Fuaddunazmi, M. (2017). Pengembangan Media Pembelajaran Berbasis Moodle pada Matakuliah Fisika Dasar. Jurnal Cakrawala Pendidikan, 36(2), 210-219. https://doi.org/10.21831/cp.v36i2.13077

Hewi, L., \& Asnawati, L. (2020). Strategi Pendidik Anak Usia Dini Era Covid-19 dalam Menumbuhkan Kemampuan Berfikir Logis. Jurnal Obsesi : Jurnal Pendidikan Anak Usia Dini, 5(1), 158. https://doi.org/10.31004/obsesi.v5i1.530

Irawan, H. (2018). Keefektifan E-Learning Sebagai Media Pembelajaran (Studi Evaluasi Model Pembelajaran E-Learning Smk Telkom Sandhy Putra Purwokerto). Jurnal Inovasi Teknologi Pendidikan, 5(1), 1-11.

Karwati, E. (2014). Pengaruh Pembelajaran Elektronik (E-Learning) terhadap Mutu Belajar Mahasiswa. Jurnal Penelitian Komunikasi, 17(1), 41-54. https://doi.org/10.20422/jpk.v17i1.5

Maonde, F. (2011). Aplikasi Penelitian Eksperimen Dalam Bidang Pendidikan dan Sosial. Unhalu Press.

Menhard. (2017). Pengaruh Pendapatan Orang Tua dan Status Sosial terhadap Minat Melanjutkan Pendidikan ke Perguruan Tinggi (Studi Kasis STIE Mahaputra Riau). Jurnal Wira Ekonomi Mikroskil, 7(1), 45-52.

Numiek Sulistyo Hanum. (2011). Keefektifan E-Learning Sebagai Media Pembelajaran (Studi Evaluasi Model Pembelajaran E-Learning SMK Telkom Sandhy Putra Purwokerto. Jurnal Pendidikan, 3(1).

Putra, N. A., \& Baharuddin, A. (2018). Pengaruh Tingkat Pendapatan Orangtua Terhadap Nilai Belajar Siswa. Jurnal Ad'ministrare, 5(2), 129-136.

Rifai, A., Sulton, S., \& Sulthoni, S. (2020). Pengembangan Media Mobile Learning Sebagai Pendukung Sumber Belajar Biologi Siswa SMA. JKTP: Jurnal Kajian Teknologi Pendidikan, 3(1), 10-17. https://doi.org/10.17977/um038v3i12019p010

Sandi, G. (2005). Pengaruh Blended Learning Terhadap Hasil Belajar Kimia Ditinjau Dari 
Kemandirian Siswa. Jurnal Pendidikan Dan Pengajaran, 241-251.

Sari, I. P. (2017). Implementasi Pembelajaran Berbasis E-Learning Menggunakan Claroline. Research and Development Journal of Education, 4(1), 75-87. https://doi.org/10.30998/rdje.v4i1.2070

Siahaan. (2003). E-learning (Pembelajaran Elektronik) sebagai Salah satu Alternatif Kegiatan Pembelajaran. Jurnal Pendidikan Dan Kebudayaan, 042.

Sugiyono. (2012). Metode Penelitian Kuantitatif, Kualitatif, R. Alfabetha.

Sukardi \& Fahrul Rozi. (2019). Pengaruh Model Pembelajaran Online Dilengkapi dengan Tutorial Terhadap Hasil belajar. Jurnal Ilmiah Penelitian Dan Pembelajaran Informatika (JIPI)., 4(2). https://jurnal.stkippgritulungagung.ac.id/index.php/jipi/index

Usman. (2013). Pengeruh model pembelajaran Kooperatif Model Pembelajaran Kooperatif dan Kemampuan IPA Terhadap Hasil Belajar Matematika. Universitas Halu Oleo.

Waryanto, N. H. (2006). Online Learning Sebagai Salah Satu Inovasi Pembelajaran. In Pythagoras (Vol. 2, Issue 1, pp. 10-23). http://staff.uny.ac.id/sites/default/files/132304807/Online Learning sebagai Salah Satu Inovasi Pembelajaran.pdf

World Health Organizaton. (2020). Naming the coronavirus disease (COVID-19) and the virus that causes it. 